\title{
Effect of Cold Water Immersion on Metabolic Rate in Humans
}

\author{
Austin Greenwood (Corresponding author) \\ Department of Exercise and Sports Science, University of Wisconsin-La Crosse, La Crosse, WI USA \\ E-mail: greenwoo.aust@uwlax.edu \\ Cordial Gillette \\ Department of Exercise and Sports Science, University of Wisconsin-La Crosse, La Crosse, WI USA \\ E-mail: cgillette@uwlax.edu
}

Received: 12-02- 2017

Accepted: 01-04- 2017

Published: 30-04- 2017

doi:10.7575/aiac.ijkss.v.5n.2p.1

URL: http://dx.doi.org/10.7575/aiac.ijkss.v.5n.2p.1

The research was supported by the Undergraduate Research and Creativity Grant.

\begin{abstract}
Background: Cold water immersion is a widely used form of cryotherapy in the active population despite the limited knowledge on its physiological effects. From an injury standpoint, reducing metabolic rate is advantageous to prevent secondary injury. In contrast, increased metabolism can be beneficial in ridding the body of unwanted metabolites. This study looked to determine the effect of cold water immersion on metabolic rate. Understanding this phenomenon will help determine appropriate clinical applications of cold water immersion and lead to a better understanding of cryotherapy in general. This study looked to determine the effect of cryotherapy in the form of waist deep cold water immersion at $9^{\circ} \mathrm{C}$ on metabolic rate. Methods: 10 participants from a university student population volunteered and completed a 15 -minute treatment of waist deep cold water $\left(9^{\circ} \mathrm{C}\right)$ immersion. Metabolic rate measurements were taken using a Jaeger Oxycon Mobile Unit for 5 minutes prior to treatment, 15 minutes of treatment, and 5 minutes post treatment for a total of 25 minutes. Statistical analysis was completed using a one way repeated measures ANOVA test to compare treatment intervals to baseline intervals. Results: Cold water immersion resulted in elevated metabolic rates for 8 of 10 participants during the first 5 minutes of treatment and for 6 of 10 in the 5 minute post treatment $(\mathrm{p}<0.05)$. A second statistical analysis excluding the first 30 second data point in the 510 and 20-25 minute treatments was used to account for movement in and out of the whirlpool. The second analysis showed the same results as the first with the exception of one participant who no longer displayed a statistically significant change in the 20-25 minute interval. Conclusion: These results indicate that cold water immersion should not be used as a measure of reducing secondary injury because of its potential to increase metabolic rate, but instead may have potential benefits in exercise recovery.
\end{abstract}

Keywords: cryotherapy, metabolism, calorimetry

\section{Introduction}

Cryotherapy found its foothold in treatment of orthopedic injury with the RICE method comprised of rest, ice, compression, and elevation proposed by Dr. Gabe Mirkin in 1978. RICE treatment was introduced as a means to decrease pain, swelling, blood flow, and avoid further injury (Mirkin \& Hoffman, 1978). More recently Dr. Mirkin has altered his stance on RICE treatment, implicating it reduces the inflammatory response and subsequently healing (Mirkin, 2016). Since its introduction, cryotherapy evolved from a simple ice pack to include a multitude of cold treatments including ice massage, cold air, and cold water immersion (Holmes \& Willoughby, 2016). The value of cryotherapy as a pain control measure was the most accepted component, showing the ability to reduce subjective pain measures and induce paresthesia after 5 to 15 minutes of treatment(Cataldi, 2013; Knight, 1995; Topp, 2013). As a natural pain reliever, clinicians utilized cryotherapy frequently in this manor since its introduction.

Advancing theory supporting cryotherapy expanded to include preventing secondary injury (Merrick, 2002; Merrick, et al., 1993; Merrick, et al.,1999). Attenuating blood flow to an area with damaged tissues and vessels was hypothesized to reduce edema and consequently secondary injury.(Ménétrier et al., 2015; Topp et al., 2013) Research indicated that cryotherapy in its various forms had the capability to reduce blood flow by inducing vasoconstriction. Using ultrasound, researchers appreciated both a reduction in blood vessel diameter and rate of blood flow through major vessels within the treatment area (Gregson et al., 2011; Holmes \& Willoughby, 2016; Ménétrier et al., 2015; Topp et al., 2013; White \& Wells, 2013). This phenomenon was generally accepted, but whether reducing blood flow to damaged tissues was beneficial is still a point of contention. 
Similarly, cryotherapy was believed to decrease secondary injury through reducing metabolism(Merrick, 2002; Merrick et al., 1999). Tissues with a reduced metabolic need would subsequently require less oxygen and be less likely to die from the hypoxic conditions resulting from the primary injury. Several studies have investigated this concept using cold water immersion and showed mixed results. In support, Knight showed a correlation between reduced core body temperature and reduced metabolism (Knight, 1995). Decreased temperature has also been associated with reduced oxygen consumption in myocardial infarction patients, resulting in decreased secondary injury (Holzer \& Behringer, 2008). This data indicates that cryotherapy has the potential to reduce secondary injury by reducing metabolic needs in orthopedic injury. In contrast, several studies have also shown the potential for an increase in metabolic rate as a result of thermogenesis and shivering (Janský et al., 1996; Lee et al., 1997; Muller et al., 2012; Sramek et al., 2000; Stocks et al., 2004).

Ultimately very little research has directly measured metabolic rate; inconsistent results regarding metabolism are in large part due to varying treatment parameters, making it difficult to determine the true impact of cryotherapy when used clinically. Previously mentioned research investigated cold water immersion using parameters unlike clinical applications to achieve changes in metabolic rate (Holzer \& Behringer, 2008; Janský et al., 1996; Knight, 1995; Lee et al., 1997; Sramek et al., 2000). The purpose of this study was to investigate the effect of cold water immersion on metabolic rate under clinical conditions. As a result, it was hypothesized that 15 minutes of cold water immersion at $9^{\circ} \mathrm{C}$ would result in increased metabolic rate compared to ambient conditions.

\section{Methods}

\subsection{Participants}

Participants consisted of 6 male and 4 female volunteers with no current injury or illness, from a university student population (mean $\pm \mathrm{SD}$, age: $20.8 \pm 1.5 \mathrm{yr}$, height: $1.76 \mathrm{~m} \pm .09 \mathrm{~m}$, mass: $75.2 \pm 13.8 \mathrm{~kg}$, Calculated BMI: $24.2 \pm$ $3.4 \mathrm{~kg} / \mathrm{m} 2$ ). The 10 participants came from a variety of activity levels. Participants provided written informed consent after an informational meeting where they were informed of the experimental protocol and potential risks. This study was approved by the University of Wisconsin-La Crosse Institutional Review Board.

\subsection{Study Design}

Participants were instructed to fast and avoid exercise for 8 hours prior to participation. Fasting also prohibited the consumption of caffeine or alcohol. Each participant was tested in the morning between 6:30 am and 8:00 am shortly after waking up. Upon arrival to the facility, participants were instructed to change into the attire in which they would enter the cold whirlpool. Participants were allowed to wear a swim suit or shorts and a t-shirt but not allowed to wear anything to insulate body heat. Height and weight measurements were taken for each participant and recorded. Participants were seated in a chair next to the cold whirlpool where they were connected to a Jaeger Oxycon Mobile unit (Becton, Dickinson, Franklin Lakes, NJ) (Eriksson, et al., 2012; Rosdahl, et al., 2010).

Experimental sessions and data collection consisted of a 25 minute period connected to a Jaeger Oxycon Mobile unit. The Oxycon Mobile unit was used to collect and calculate metabolic rate throughout the experiment using the indirect calorimetry function. The Oxycon Mobile unit was calibrated before each session using a reference gas of $14.97 \%$ O2, 4.96\% CO2, and balance N2. The output of the Oxycon Mobile was given in $\mathrm{kcal} / \mathrm{min}$. The Oxycon Mobile collected data at regular 30 second intervals during the entirety of data collection. The first 5 minutes were collected while the participant was seated outside of the whirlpool; this measure was used as a baseline. The baseline was collected in close proximity to the whirlpool to reduce the effect of movement between treatments. The next 15 minute period constituted the treatment where participants were moved into a seated position in the whirlpool. An Icebox IT (Cold Tub, West Harwich, MA) was used to perform the cold water immersion treatments. The cold whirlpool was set to $9^{\circ} \mathrm{C}$ based on clinical parameters at the University and prior research which used parameters between $5^{\circ} \mathrm{C}$ and $15^{\circ} \mathrm{C}$ (Gregson et al., 2011; Holmes \& Willoughby, 2016; Janský et al., 1996, 2006; Lee et al., 1997). A 15-minute treatment time was again based on prior research and the clinical applications at the University (Gregson et al., 2011; Janský et al., 1996, 2006; Lee et al., 1997; Mark A. Merrick \& McBrier, 2010). Participants were submerged approximately to the umbilicus to simulate clinical conditions. At the conclusion of the treatment, participants were moved back to the seated position outside of the whirlpool where data was collected for another 5 minutes.

\subsection{Statistical Analysis}

The 25 minutes of data collection were divided into 5 intervals of 5 minutes. The first 5 minutes $(0-5)$ was labeled as the baseline. The 15 minutes of treatment was subdivided into the first 5 minutes (5-10), second 5 minutes (10-15), and third 5 minutes (15-20). The last 5 minutes (20-25) was labeled as the post treatment interval. Resulting intervals contained 10 data points each. The 10 data points were averaged and used to complete a one way repeated measures ANOVA test to determine significance at a level of level of $p=0.05$. Statistical analysis was performed with SPSS (version 23.0, SPSS Inc., USA). A second statistical analysis was performed excluding the first data point entering and exiting the cold whirlpool to account for effects of movement on metabolic rate. 


\section{Results}

The repeated measures ANOVA test with verified normality indicated the greatest difference between the 5 minute baseline (0-5 minute interval) and the first 5 minutes in the whirlpool (5-10 minute interval). A difference was also present between the 5 minute baseline (0-5 minute interval) and the 5 minute post treatment measurements $(20-25$ minute interval) (Figure 1).

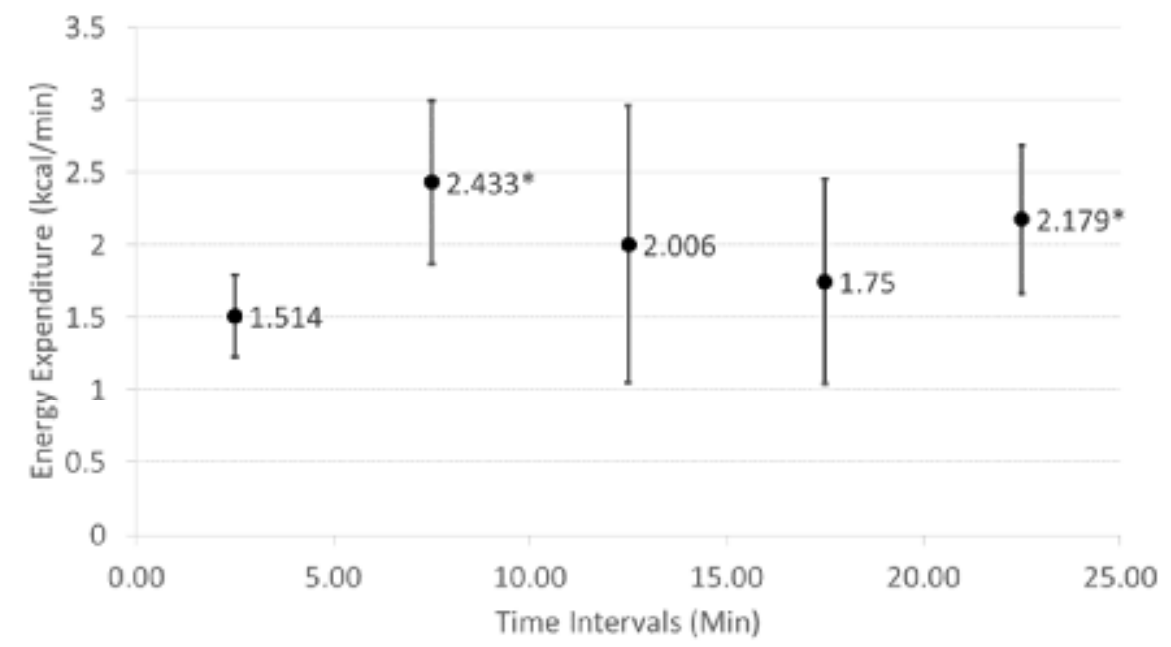

Figure 1. Mean Energy Expenditure per Interval. Data represented as collective average for each interval \pm SD. ${ }^{*}$ denotes significant increase compared to baseline $(p<0.05)$.

Table 1 contains the average interval data for each Participant during the 25-minute session. Average metabolic rate over the treatment period increased $(\mathrm{p}<0.05)$ immediately after entering the cold whirlpool $(5-10$ minute interval) for 8 out of 10 participants and increased in 6 out of 10 participants after exiting the whirlpool (20-25 minute interval) (Table 1). Participants 4-6 had significant differences compared to baseline during all treatment periods while participant 7 had no changes in metabolic rate through the entirety of the experiment.

Table 1. Changes in metabolic rate during 5 minute baseline, 15 minute CWI treatment, and 5 minute post treatment

\begin{tabular}{llllll}
\hline Treatment Interval & $0-5$ & $5-10$ & $10-15$ & $15-20$ & $20-25$ \\
\hline Participant 1 & $1.63 \pm 0.28$ & $2.63 \pm 0.94^{*}$ & $1.94 \pm 0.19^{*}$ & $1.83 \pm 028$ & $2.37 \pm 0.35^{*}$ \\
Participant 2 & $1.26 \pm 0.17$ & $1.97 \pm 0.93^{*}$ & $1.29 \pm 0.15$ & $1.29 \pm 0.21$ & $1.39 \pm 0.5$ \\
Participant 3 & $1.08 \pm 0.08$ & $1.73 \pm 0.62^{*}$ & $1.15 \pm 0.14$ & $1.08 \pm 0.08$ & $1.57 \pm 0.49^{*}$ \\
Participant 4 & $1.05 \pm 0.10$ & $1.94 \pm 0.34^{*}$ & $1.73 \pm 0.12^{*}$ & $1.51 \pm 0.14^{*}$ & $1.74 \pm 0.34^{*}$ \\
Participant 5 & $1.75 \pm 0.18$ & $2.83 \pm 1.02^{*}$ & $2.31 \pm 0.28^{*}$ & $2.06 \pm 0.25^{*}$ & $2.91 \pm 0.53^{*}$ \\
Participant 6 & $1.73 \pm 0.27$ & $2.72 \pm 0.60^{*}$ & $3.52 \pm 0.46^{*}$ & $2.35 \pm 0.27^{*}$ & $2.84 \pm 0.94^{*}$ \\
Participant 7 & $1.62 \pm 0.42$ & $2.06 \pm 0.76$ & $1.46 \pm 0.29$ & $1.26 \pm 0.34$ & $2.16 \pm 0.95$ \\
Participant 8 & $1.78 \pm 0.33$ & $2.23 \pm 0.75$ & $1.50 \pm 0.65$ & $1.36 \pm 0.35 \#$ & $2.42 \pm 0.79^{*}$ \\
Participant 9 & $1.48 \pm 0.32$ & $2.61 \pm 0.68^{*}$ & $1.30 \pm 0.25$ & $1.36 \pm 0.29$ & $1.99 \pm 0.71$ \\
Participant 10 & $1.75 \pm 0.43$ & $3.61 \pm 0.45^{*}$ & $3.86 \pm 0.29^{*}$ & $3.40 \pm 0.45^{*}$ & $2.42 \pm 0.77$
\end{tabular}

Data represented as mean $\pm \mathrm{SD}$ over the 5-minute treatment period. * denotes significant increase compared to baseline. \# denotes significant decrease compared to baseline $(\mathrm{p}<0.05)$.

Statistical analysis was run a second time excluding the first 30 second data point in the 5-10 and 20-25 minute treatments which involved movement in and out of the whirlpool, respectively. The second statistical analysis resulted in the differences as the first except for one interval in which participant 8 no longer had a change in the 2025-minute point.

\section{Discussion}

This study looked to determine the effect of cryotherapy in the form of waist deep cold water immersion at $9^{\circ} \mathrm{C}$ on metabolic rate. In agreement with the hypothesis, cold water immersion caused increased metabolic rate during treatment compared to baseline. Most significant increases occurred during the first 5 minutes of cold water immersion or during the 5-minute post cold water immersion interval. Increases at these points presented as rapid 
increases in metabolic rate that deteriorated with time. Some participants experienced sustained significant elevations into the successive intervals. Contrary to the hypothesis, metabolic rate did not stay significantly elevated during the entire treatment, and some participants experienced decreases in metabolic rate at some intervals. Despite these decreases, only one interval yielded a significant decrease.

It is possible that the increase in metabolic rate at the 5-10 and 20-25 minute intervals was due to movement during the transition in and out of the whirlpool. Movement would cause an increase in metabolic rate that could not be attributed to the cold water immersion treatment (Romero et al., 2016; Wang et al., 2001). To minimize the effect of movement on metabolic rate, participants were strategically positioned to require as little movement as possible when moving in and out of the whirlpool. A second statistical analysis was also run excluding the first 30 second point of both the 5-10 and 20-25 minute periods. The first data point in the respective intervals would contain the time transitioning into and out of the whirlpool. By excluding this point, it was more likely that the difference in metabolic rate was due to the treatment and not due to the movement. Under the new standard, only one significant data point was lost. Conservation of statistical significance indicates deviation due to the treatment, not the movement in and out of the whirlpool.

As a result, this data indicates that clinical applications of cold water immersion cause increases in metabolic rate, perhaps as a mechanism to compensate for the change in environment. Several others identified a similar effect under different temperatures, levels of submersion, and duration of submersion. Janský et al. showed a significant increase in metabolic rate using head out immersion at $14^{\circ} \mathrm{C}$ for 60 minutes (Janský et al., 1996). Sarmek et al. investigated the effect of altering water temperature using head out immersion for 60 minutes at $14^{\circ} \mathrm{C}$ and $20^{\circ} \mathrm{C}$. Findings showed increases in metabolic rate of $350 \%$ at $14^{\circ} \mathrm{C}$ and $93 \%$ at $20^{\circ} \mathrm{C}$ (Sramek et al., 2000). It should be noted that immersion at $14^{\circ} \mathrm{C}$ resulted in a shivering response, likely responsible for the large increase in metabolic rate. Lee et al. altered three variables including the level of immersion, temperature, and patient activity. Immersion levels were set at the knee, hip, and ankle; water temperatures were set to $15^{\circ} \mathrm{C}$ and $25^{\circ} \mathrm{C}$; and activities levels were at rest and while exercising. The hip levels, $15^{\circ} \mathrm{C}$, at rest testing parameters were most similar to the present study. Treatment times in this case were set at 135 minutes or the point when body temperature dropped to $35^{\circ} \mathrm{C}$. Results of Lee et al. showed a significant increase in metabolic rate at rest in $15^{\circ} \mathrm{C}$ immersion at the shoulder and nonsignificant increases when immersed to the hip or knee (Lee et al., 1997). Mueller et al conducted a study aimed at lower body cold water immersion at $13^{\circ} \mathrm{C}$ for 60 minutes, but similar to Lee et al., only showed non-significant increases in metabolic rate.

The present study showed increases in metabolic rate analogous to the prior mentioned studies under clinical circumstances. Consequently, comparison is limited because each of the prior studies were not done at clinical conditions either as a result of their duration, depth of immersion, or both. The majority of the studies elicited a significant increase in metabolic rate from shivering which resulted from immersion above the shoulder for at least 60 minutes. This study did not elicit any observable shivering during the treatment period. In similar studies where immersion was set to the hip, both resulted in no significant data despite lasting at least 4 times as long as this study. This discrepancy could be attributed to the frequency of data collection. Lee et al. collected metabolic data at minutes 15, 30, 45, and 60 while Muller et al. collected data during minutes 5-10, 25-30, and 45-50. Neither case acquired measurements for minutes 0-5 which were the most significant data points in this study (Lee et al., 1997; Muller et al., 2012).

The findings of this study and the prior mentioned studies conflict with the original hypothesized use of cryotherapy as a means to decrease secondary injury through a reduction in metabolic rate. Knight presented a correlation between decreasing body temperature and decreasing metabolism (Knight, 1995). This study did not measure core body temperature and cannot be compared, but Sramek et al. and Lee et al. showed eventual decreases in metabolic rate after an initial period of increase due to shivering (Lee et al., 1997; Sramek et al., 2000). The present study also showed the potential for a decrease in metabolic rate after the initial increase after entering the cold whirlpool. It can be reasoned that metabolism begins to decrease after accommodation or a failed attempt to maintain core body temperature. As a result, it is likely there is a permutation of cryotherapy that would elicit a decreased metabolic rate.

Based on the findings of this study, cold water immersion should not be used clinically to reduce secondary injury after acute injury because of its potential to increase metabolic rate. This notion is already reflected in clinical use. Instead, cold water immersion could be more beneficially applied to exercise recovery where it is already conventionally used, possibly because exercise induced damage is thought to induce a different inflammatory response compared to trauma (Merrick, 2002). In a post exercise case, an increased metabolic rate could accelerate recovery by a reducing muscle damage and increasing recovery of submaximal muscle strength (Merrick, 2002; Roberts et al., 2014). It is well known that cryotherapy immediately before exercise reduces speed, power, and agility, but there may be an ideal time period between two bouts of exercise where an increase in metabolic rate due to cold water immersion could be beneficial (Parouty et al., 2010; Roberts et al., 2014). These findings would support the theory proposed by Roberts et al. that cold water immersion could be used between successive bouts of training (Roberts et al., 2014). This was proposed after finding that cold water immersion aided in the recovery of submaximal strength between two exercise sessions. Conversely, this is inconsistent with results obtained by Parouty et al. where a reduction in performance was found in $100 \mathrm{~m}$ swimmers. The major difference being Parouty 
et al. used a shorter window between cold water immersion treatments and the second bout of exercise (Parouty et al., 2010).

Limitations to this study stem from compliance of the participants, the global measures of metabolism, and the failure to take core body temperature. While participants were instructed to fast for 8 hours, not consume alcohol or caffeine, and avoid exercising prior to participation, it is impossible to ensure complete adherence. There is variation based on activity of each participant in the morning prior to reporting. Some participants may have reported immediately after waking while some may have engaged in a longer morning routine. These factors could affect the stability of the baseline measurement. Inability to measure the metabolic rate locally also limited the specificity of the results. Metabolic rate was measured globally instead of obtaining the metabolic rate of the treated tissues. This broad nature of the measurement makes it difficult to distinguish the metabolic contributions of the treated tissues verses the non-treated tissues. While it is assumed that changes in metabolic rate were a result of the treatment applied to the lower body, the contributions of the upper body to metabolic rate cannot be ignored. It is possible that non-submerged tissue could have affected metabolic measurements. The lack of core body temperature measurement also made it impossible to compare changes in core body temperature to metabolic changes that is present in much of the current research.

\section{Conclusion}

This study was created with the purpose of determining the effect of lower body cold water immersion on systemic metabolic rate. Cold water immersion is widely used in athletics but has little research uncovering its true effects. Based on traditional applications of cryotherapy, it may be expected that cold water immersion results in a reduction in metabolic rate. Conversely, investigation into cold water immersion has yielded evidence of increased metabolic rate. Based on the findings here, clinical applications of cold water immersion for 15 minutes at $9^{\circ} \mathrm{C}$ resulted in an increase in metabolism, possibly as a coping mechanism to a changing environment. Cold water immersion, therefore, should not be indicated as a treatment for acute injury but instead may have a role in exercise recovery as is already observed clinically. This role may be found in athletes participating in multiple bouts of exercise spaced throughout the day. Continued research is needed to determine where cold water immersion fits in the realm of both injury and exercise recovery. This study used all healthy participants and had no exercise component, limiting its application to injury and exercise recovery. Continued research using the methods described in this study could look to measure metabolic changes in a population of acutely injured athletes, athletes with documented chronic injuries, or athletes after participating in intense exercise. Similarly, further variations of this study could include using different cryotherapy treatments including ice bags, ice massage, and cold air treatments to determine their effects of metabolism. Lastly, treatment parameters including temperature and duration of cryotherapy treatment should be altered to help determine which parameters are most effective in eliciting a desired metabolic response.

\section{References}

Cataldi, J. K., Pritchard, K. A., Hart, J. M., \& Saliba, S. A. (2013). Cryotherapy Effects, Part 2: Time to Numbness Onset and Numbness Duration. International Journal of Athletic Therapy \& Training, 18(5), 26-28.

Eriksson, J. S., Rosdahl, H., \& Schantz, P. (2012). Validity of the Oxycon Mobile metabolic system under field measuring conditions. European Journal of Applied Physiology, 112(1), 345-355. https://doi.org/10.1007/s00421011-1985-1

Gregson, W., Black, M. A., Jones, H., Milson, J., Morton, J., Dawson, B., ... Green, D. J. (2011). Influence of Cold Water Immersion on Limb and Cutaneous Blood Flow at Rest. The American Journal of Sports Medicine, 39(6), 1316-1323. https://doi.org/10.1177/0363546510395497

Holmes, M., \& Willoughby, D. (2016). The Effectiveness of Whole Body Cryotherapy Compared to Cold Water Immersion: Implications for Sport and Exercise Recovery. International Journal of Kinesiology and Sports Science, 4(4). https://doi.org/10.7575/aiac.ijkss.v.4n.4p.32

Holzer, M., \& Behringer, W. (2008). Therapeutic hypothermia after cardiac arrest and myocardial infarction. Best Practice \& Research. Clinical Anaesthesiology, 22(4), 711-728.

Janský, L., Janáková, H., Ulicný, B., Srámek, P., Hosek, V., Heller, J., \& Parízková, J. (1996). Changes in thermal homeostasis in humans due to repeated cold water immersions. Pflügers Archiv: European Journal of Physiology, 432(3), 368-372.

Janský, L., Matousková, E., Vávra, V., Vybíral, S., Janský, P., Jandová, D., ... Kunc, P. (2006). Thermal, cardiac and adrenergic responses to repeated local cooling. Physiological Research / Academia Scientiarum Bohemoslovaca, 55(5), 543-549.

Knight, K. L. (1995). Cryotherapy in sport injury management. Champaign, IL: Human Kinetics.

Lee, D. T., Toner, M. M., McArdle, W. D., Vrabas, I. S., \& Pandolf, K. B. (1997). Thermal and metabolic responses to cold-water immersion at knee, hip, and shoulder levels. Journal of Applied Physiology (Bethesda, Md.: 1985), 82(5), 1523-1530. 
Ménétrier, A., Béliard, S., Ravier, G., Mourot, L., Bouhaddi, M., Regnard, J., \& Tordi, N. (2015). Changes in femoral artery blood flow during thermoneutral, cold, and contrast-water therapy. The Journal of Sports Medicine and Physical Fitness, 55(7-8), 768-775.

Merrick, M. A. (2002). Secondary Injury After Musculoskeletal Trauma: A Review and Update. Journal of Athletic Training, 37(2), 209-217.

Merrick, M. A., Knight, K. L., Ingersoll, C. D., \& Potteiger, J. A. (1993). The effects of ice and compression wraps on intramuscular temperatures at various depths. Journal of Athletic Training, 28(3), 236-245.

Merrick, M. A., \& McBrier, N. M. (2010). Progression of Secondary Injury After Musculoskeletal Trauma--A Window of Opportunity? Journal of Sport Rehabilitation, 19(4), 380-388.

Merrick, M. A., Rankin, J. M., Andres, F. A., \& Hinman, C. L. (1999). A preliminary examination of cryotherapy and secondary injury in skeletal muscle. Medicine and Science in Sports and Exercise, 31(11), 1516-1521.

Mirkin, G. (2016, October 13). Why Ice Delays Recovery. Retrieved from http://www.drmirkin.com/fitness/whyice-delays-recovery.html

Mirkin, G., \& Hoffman, M. (1978). The sports medicine book. Boston: Little, Brown.

Muller, M. D., Kim, C.-H., Seo, Y., Ryan, E. J., \& Glickman, E. L. (2012). Hemodynamic and Thermoregulatory Responses to Lower Body Water Immersion. Aviation, Space, and Environmental Medicine, 83(10), 935-941. https://doi.org/10.3357/ASEM.3311.2012

Parouty, J., Al Haddad, H., Quod, M., Leprêtre, P. M., Ahmaidi, S., \& Buchheit, M. (2010). Effect of cold water immersion on 100-m sprint performance in well-trained swimmers. European Journal of Applied Physiology, 109(3), 483-490. https://doi.org/10.1007/s00421-010-1381-2

Roberts, L. A., Nosaka, K., Coombes, J. S., \& Peake, J. M. (2014). Cold water immersion enhances recovery of submaximal muscle function after resistance exercise. American Journal of Physiology - Regulatory, Integrative and Comparative Physiology, 307(8), R998-R1008. https://doi.org/10.1152/ajpregu.00180.2014

Romero, B., Coburn, J. W., Brown, L. E., \& Galpin, A. J. (2016). Metabolic Demands of Heavy Metal Drumming. International Journal of Kinesiology and Sports Science, 4(3). https://doi.org/10.7575/aiac.ijkss.v.4n.3p.32

Rosdahl, H., Gullstrand, L., Salier-Eriksson, J., Johansson, P., \& Schantz, P. (2010). Evaluation of the Oxycon Mobile metabolic system against the Douglas bag method. European Journal of Applied Physiology, 109(2), 159171. https://doi.org/10.1007/s00421-009-1326-9

Sramek, P., Simeckova, M., Janský, L., Savlikova, J., \& Vybiral, S. (2000). Human physiological responses to immersion into water of different temperatures. European Journal of Applied Physiology, 81(5), 436-442. https://doi.org/10.1007/s004210050065

Stocks, J. M., Taylor, N. A. S., Tipton, M. J., \& Greenleaf, J. E. (2004). Human physiological responses to cold exposure. Aviation, Space, and Environmental Medicine, 75(5), 444-457.

Topp, R., Ledford, E. R., \& Jacks, D. E. (2013). Topical Menthol, Ice, Peripheral Blood Flow, and Perceived Discomfort. Journal of Athletic Training, 48(2), 220-225. https://doi.org/10.4085/1062-6050-48.1.19

Wang, Z., Heshka, S., Zhang, K., Boozer, C. N., \& Heymsfield, S. B. (2001). Resting Energy Expenditure: Systematic Organization and Critique of Prediction Methods*. Obesity, 9(5), 331-336. https://doi.org/10.1038/oby.2001.42

White, G. E., \& Wells, G. D. (2013). Cold-water immersion and other forms of cryotherapy: physiological changes potentially affecting recovery from high-intensity exercise. Extreme Physiology \& Medicine, 2(1), 26. https://doi.org/10.1186/2046-7648-2-26 